\title{
VISÃO DOS CAFEICULTORES SOBRE O MARKETING DE SERVIÇOS OFERTADO PELOS CORRETORES DE CAFÉ EM CAPARAÓ - MG
}

\author{
COFFEE GROWERS VIEW ON MARKETING SERVICES OFFERED BY COFFEE \\ BROKERS IN CAPARAÓ - MG
}

Diony Gregório Prado Lopes ${ }^{1}$, Leonardo dos Santos Ferreira ${ }^{2}$, Rodrigo da Silva Freitas $^{3}$, Altamiro Lacerda de Almeida Junior ${ }^{4}$, Wagner dos Reis Marques Araújo ${ }^{5}$

\begin{abstract}
1 Universidade do Estado de Minas Gerais - Unidade Carangola, Brasil, e-mail: dionylopes17@gmail.com

2 Universidade do Estado de Minas Gerais - Unidade Carangola, Brasil, e-mail: contato.leonardoferreira@gmail.com

3 Universidade do Estado de Minas Gerais - Unidade Carangola, Brasil, e-mail: rodrigofreitas.tst@outlook.com

${ }^{4}$ Universidade do Estado de Minas Gerais - Unidade Carangola; Instituto Federal de Educação, Ciências e Tecnologia - Sudeste de Minas Gerais - Campus Avançado de Cataguases; Grupo UNIS Faculdades Integradas de Cataguases, Brasil, e-mail: altamiro@unis.edu.br

5 Universidade do Estado de Minas Gerais - Unidade Carangola, Brasil, e-mail: marquesreis@hotmail.com
\end{abstract}

\author{
ART ICLE INFO \\ Article history: \\ Received 2019-08-03 \\ Accepted 2019-09-06 \\ Available online 2019-09-06
}

Palavras-chave: Marketing de serviços. Corretores de café. Cafeicultores.

Keywords: Service marketing. Coffee brokers. Coffee growers.

RESUMO. O presente artigo descreve a relevância do marketing e suas ferramentas para as organizações. Em serviços, o artigo descreve e analisa o marketing especifico do setor, apresentando as ferramentas a serem estudadas pelos prestadores, afim de minimizar os impactos causados pelos aspectos dos serviços, baseando-se em seu composto, conhecido como oito P's, responsáveis por tangibilizar qualidade na prestação dos mesmos. A metodologia foi definida como descritiva e abordagem qualitativa, auxiliada por pesquisas bibliográficas, com aplicação de entrevistas semiestruturadas para a coleta de dados através de amostra composta por 40 (quarenta) cafeicultores do município de Caparaó - MG. Procurou-se identificar a visão dos cafeicultores em relação às estratégias de marketing de serviços utilizadas pelos comércios de corretagem de café do município e a importância da utilização de tais estratégias na expansão competitiva, diante de um mercado saturado. Constatou-se que na visão dos cafeicultores, a inovação competitiva deu lugar ao conformismo com o padrão mercadológico trabalhado atualmente pelo setor e o marketing utilizado é ineficiente, não alcançando uma comunicação direta com o público-alvo.

\begin{abstract}
This article describes the relevance of marketing and its tools to organizations. In services, the article describes and analyzes the specific marketing of the sector, presenting the tools to be studied by the providers, in order to minimize the impacts caused by the service aspects, based on its compound, known as eight Ps, responsible for tangible quality in providing them. The methodology was defined as descriptive and qualitative approach, aided by bibliographic research, with the application of semi-structured interviews for data collection through a sample composed of 40 (forty) coffee growers from Caparaó - MG. We sought to identify the view of coffee farmers in relation to the marketing strategies of services used by the municipality's coffee brokerage trades and the importance of using such strategies in competitive expansion, facing a saturated market. It was found that in the coffee growers' view, competitive innovation has given way to conformity with the market standard currently
\end{abstract}


being worked by the sector and the marketing used is inefficient, not reaching direct communication with the target audience.

\section{Introdução}

O marketing é composto de ferramentas a serem trabalhadas nos mais variados ramos de negócios. Seja na comercialização de produtos ou na prestação de serviços, o objetivo das empresas é atrair novos consumidores e fidelizar o maior número de clientes possíveis.

O marketing de serviços objetiva através do conhecimento de seus aspectos e, sobretudo, de seu composto característico de oito Ps, a apresentação ao cliente dos valores não financeiros do serviço ofertado, tornando tangível qualidades peculiares, distanciando competitivamente de outras empresas do mesmo ramo que não utilizam das mesmas ações de impulsionamento mercadológico.

Com a expansão das lavouras cafeeiras e consequentemente a expansão da produção, os pequenos comércios de café, responsáveis pela intermediação entre o produtor e os grandes comércios de despacho da produção, se pulverizaram pelas regiões produtivas. Tais intermediários, mantem contato direto com o produtor. Por essa ligação direta, há a necessidade de se trabalhar com qualidade, a fim de conquistar e manter clientes dentro de um mercado saturado. O café soma importante peso econômico entre as commodities exportadas pelo Brasil e constitui uma das principais fontes de renda de algumas famílias brasileiras, principalmente da cidade de Caparaó - Minas Gerais, recorte utilizado para este estudo de caso. O presente estudo tem por objetivo analisar a percepção dos cafeicultores da cidade de Caparaó sobre as estratégias de marketing de serviços utilizadas pelos corretores de café do município.

\section{Referencial Teórico}

\subsection{Serviços}

Para atender as necessidades demandadas da sociedade, bens e serviços são produzidos. Caracteriza-se como bens, fatores de produção palpáveis que oferecem resultados materiais ao adquirente. Diferentemente, os serviços possuem características intangíveis, transferidas a prestadores, com o objetivo de atender as necessidades nãomateriais explicitadas por clientes (RATHMELL, 1966).

Talvez a distinção fundamental entre bens e serviços esteja no fato de que clientes normalmente derivam valor de serviços sem obter a propriedade de quaisquer elementos tangíveis; entre as exceções estão serviços de alimentação e instalação de peças avulsas durante a entrega de serviços de conserto (LOVELOCK; WIRTZ, 2006, p. 9). 
Tanto Lovelock e Wright (2001) como Kotler e Keller (2006), afirmam que serviços é qualquer ato ou desempenho acordado entre duas partes ou mais, com características essencialmente intangíveis, podendo estar ou não ligados a um produto físico, resultando em benefícios às partes envolvidas no processo. Para os autores Urdan e Urdan (2006), os serviços tornam perceptíveis benefícios e custos, mesmo não havendo a posse tangível de bens.

A prestação de serviços representa um dos principais pilares da economia mundial. No Brasil, segundo levantamento do Instituto Brasileiro de Geografia e Estatísticas - IBGE (2019a), os serviços tiveram participação de 82\% dentro do setor terciário no ano de 2018 , com representatividade de $60,1 \%$ do Produto Interno Bruto. A representatividade dos serviços no PIB brasileiro, crava a importância do setor para o desenvolvimento econômico do país. O referido setor, impulsiona efetivamente a economia e pulveriza novas oportunidades de negócios formais e informais, gerando novos vínculos empregatícios, produzindo riquezas macroeconômicas de grandezas dimensionais. Para Las Casas (2000), quanto maior o poder aquisitivo da população, maior será a representatividade do setor de serviços na economia.

\subsubsection{Aspectos dos Serviços}

Conforme Stefano et al. (2004, p. 4), "quando nos referimos a serviços podemos dizer que são intangíveis, já que não podem ser vistos, provados, sentidos, ouvidos ou cheirados antes de serem comprados". Por sua intangibilidade, torna-se difícil predefinir os resultados finais dos serviços, gerando dúvidas ao adquirente quanto à qualidade. Tal atributo dificulta ainda, segundo os autores, a percepção do cliente no que se refere aos resultados que a prestação do possível serviço traria.

Embora sejam intangíveis, os serviços possuem evidências perceptíveis que devem ser bem trabalhadas de forma a aumentar sua tangibilidade (LAS CASAS, 2007). Os prestadores de serviços devem cuidar da apresentação das instalações, dos colaboradores, dos cartões de visita, sites e redes sociais, de forma a maximizar as evidências da qualidade da prestação de serviços, "a empresa deve procurar demonstrar toda a parte concreta e material da melhor maneira possível, visando projetar a imagem desejada" (LAS CASAS, 2007, p. 204).

Kahtalian (2002, p. 21) afirma que "todo serviço tem um momento em que sua produção e consumo são simultâneos, inseparáveis". A inseparabilidade mantém a proximidade entre o cliente e o prestador do serviço, pois o consumo tende a ser momentâneo ao processo de produção, não sendo possível a estocagem. Diferente da comercialização de produtos, onde geralmente se produz primeiro e expõe a produção para a análise e potencial compra, a comercialização de serviços requer necessariamente, um ajuste entre a demanda e a oferta. Muitas vezes na prestação de serviços é comum a participação direta e indireta do 
consumidor com a produção do referido serviço (URDAN; URDAN, 2006). De acordo com Kotler (1998, p. 414), "como o cliente está também presente enquanto o serviço é produzido, a interação fornecedor-cliente é uma característica especial do marketing de serviços. Ambos afetam o resultado do serviço".

Para os autores Las Casas (2007) e Deming (1990), a presença do cliente no ambiente em que será prestado o trabalho, faz com que o produtor do serviço necessite atuar de forma que não desaponte o adquirente, pois a sua atuação é tangível aos olhos de quem o acompanha e se as exigências forem bem pautadas, agregará valores ao seu trabalho.

Existe grande variabilidade no setor de serviços, ou seja, a qualidade do trabalho ofertado depende do cliente e inquestionavelmente do prestador, podendo este ter uma eficiência pior ou melhor do que os outros disponíveis no mercado e dispostos a cumprir as mesmas atividades. "Como dependem de por quem, onde e quando são fornecidos, os serviços são altamente variáveis." (KOTLER; KELLER, 2006, p. 400). Essa característica de variabilidade torna a padronização dos serviços mais difícil, pois as situações se diferem de serviço para serviço, além disso, soma-se a interação entre os executores do serviço e os clientes.

De fato, a maioria dos serviços é, na prática, uma conjugação de processos e pessoas. Se os processos não estão bem conduzidos, se as pessoas não são as adequadas ou mesmo quando ocorre a substituição de determinadas pessoas, a qualidade do serviço pode estar comprometida (KAHTALIAN, 2002, p. 25).

O aperfeiçoamento dos colaboradores é essencial a fim de minimizar os impactos negativos ocasionados pela individualidade de cada um, colocando a mercê a tangibilidade da empresa, visto que em um setor de intangíveis, a reputação da empresa é o principal elemento que será examinado antes de uma eventual contratação. "Como o perfil das pessoas é variado, pode ser que uma pessoa faça mal o serviço e acabe com a credibilidade de todas as outras e principalmente da marca e confiabilidade do estabelecimento" (FARIA, 2011, p. 22).

Os serviços são sensíveis à demanda, sendo produzidos apenas quando a necessidade do cliente é manifesta, não sendo possível estocá-los e aguardar até que sejam adquiridos. "A perecibilidade dos serviços não é problema quando a demanda é estável, porque é fácil antecipar sua prestação. Quando a demanda é flutuante, as empresas de serviços enfrentam problemas difíceis" (KOTLER, 1998, p. 416).

Para que uma prestadora de serviços estabeleça controle entre a demanda existente e a oferta, deve-se adotar práticas estratégicas que conquiste e faça com que o cliente se interesse a conhecer suas ofertas, alimentando potencialmente a demanda com serviços momentâneos que cative a atenção, seja pelo preço ou pela praticidade. "Quanto à característica da perecibilidade, é necessário muito esforço para igualar a demanda à oferta." (LAS CASAS, 2006, p. 289). 


\subsection{Marketing}

O desenvolvimento da sociedade fomentou a demanda por diversos e diferentes bens e serviços. As exigências cada vez maiores por parte dos consumidores e a competitividade mercadológica, tem exigido mais especialização por parte das organizações (ROCHA; CHRISTENSEN, 1999). "Marketing é o processo de planejamento e execução da concepção, preço, promoção e distribuição de ideias, bens e serviços, organizações e eventos para criar trocas que venham a satisfazer objetivos individuais e organizacionais." (BOONE; KURTZ, 1998, p. 6). É neste contexto, buscando otimizar os resultados das organizações que se aplica o marketing.

Para Rocha e Christensen (1999), o marketing utiliza-se de um conjunto de princípios, estratégias e técnicas como ferramentas necessárias no ajuste entre as ofertas de bens e serviços e o mercado consumidor. Os autores afirmam ainda, que a satisfação dos consumidores e o atendimento às suas necessidades, são tarefas primordiais das organizações. "Com a especialização, o processo de troca tornou-se mais fácil, uma vez que a sociedade beneficiou-se com a qualidade e produtividade dos mais capacitados." (LAS CASAS, 2006, p. 3).

O mercado ofertante precisa conhecer precisamente as características do que é explicitado pelo mercado consumidor, traçando estratégias de marketing para atendê-lo. Conhecer quais produtos e serviços são demandados, trabalhar com eficiência para ofertálos em pontos estratégicos, com importe aceitável dentro do nicho trabalhado e utilizar-se de uma comunicação precisa para alcançar o público-alvo, são fundamentais para ganhar espaço dentro de um mercado concorrido (SHIMOYAMA; ZELA, 2002).

\subsubsection{Composto de Marketing}

O composto de marketing caracteriza-se por ferramentas estratégicas controláveis, denominadas quatro Ps, referindo-se a produto, praça, preço e promoção, ferramentas estas, pilares principais da mercadologia. "O composto de marketing é o conjunto de ferramentas que a empresa usa para atingir seus objetivos de marketing no mercado-alvo." (KOTLER, 1998, p. 97). Sua importância para um negócio de sucesso é evidente, uma vez que este implica-se em influenciar pessoas, entender as necessidades de seus consumidores e seus desejos (SILVA et al., 2018).

O produto é o bem tangível ofertado ao mercado consumidor. A inovação e a incorporação de atributos ignorados pela concorrência, ocasionam valores percebidos, agregando uma melhor visibilidade aos produtos. Segundo Urdan e Urdan (2006, p. 30), o produto "é um objeto oferecido ao consumidor que satisfaz necessidades e atende desejos". [...] o produto, para o marketing, transcende sua forma externa. Isso ocorre porque o produto 
que a organização oferece deve ser visto não a partir do que ele é para a organização, mas a partir do que ele significa para o consumidor (ROCHA; CHRISTENSEN, 1999, p. 86).

A praça é o ponto chave na distribuição dos produtos. Referindo-se aos locais de exposição e distribuição, Stefano et al. (2004, p. 3) afirmam que a praça é uma ferramenta importante do marketing, onde inclui-se "várias atividades assumidas pela empresa para tornar o produto acessível e disponível aos consumidores-alvos". Para Cobra (2009), as fábricas, depósitos e distribuidores, precisam estar instalados em pontos estratégicos, para que a cobertura de atendimento às demandas seja eficiente, fazendo com que o produto certo esteja no local exato no momento que a necessidade ou desejo pelo mesmo for explicitado pelo consumido. Nesse sentido, Pires et al. (2019) relatam que a praça envolve uma rede de instituições que juntas interligam produtores e consumidores.

A variável preço refere-se ao importe monetário, ou seja, o valor que o cliente pagará pelo produto. O preço deve estar em consentimento com a qualidade percebida e o nicho ao qual o referido produto é direcionado (URDAN; URDAN, 2006). Os autores Shimoyama e Zela (2002, p. 14) afirmam que o preço atribuído ao produto "deve ser suficientemente alto, para proporcionar lucro a quem o está produzindo ou comercializando, porém não pode ser tão alto que desestimule a compra”. Pires et al. (2019) informam que o preço reúne um conjunto de elementos monetários que irão compor o valor do produto.

Definido o produto, o nicho ao qual ele será direcionado e o preço a ele atribuído, é necessário trabalhar a comunicação mercadológica para alcançar o público-alvo. A promoção tem por objetivo tornar o produto visível através de estratégias de publicidade direcionada ao nicho trabalhado. "Promover se relaciona com a função de informar, persuadir e influenciar a decisão de compra do consumidor." (LAS CASAS, 2006, p. 377). A comunicação envolve diversas ações para promover um produto ou serviço (PIRES et al., 2019).

Os elementos estratégicos do marketing oferecem ao ofertante a capacidade de conhecer as tendências do público-alvo e quando bem trabalhados, torna-se perceptível quais produtos os consumidores querem, como querem e quando querem, atingindo êxito no processo de troca (VARADARAJAN, 2009). Todos os elementos que compõem o marketing, segundo Hansen (2016), devem ser executados em conjunto pela empresa, objetivando maximizar a eficiência no alcance de seus objetivos.

\subsection{Marketing de Serviços}

Diferentemente do mercado de bens, onde é possível apresentar características tangíveis aos consumidores finais, o mercado de serviços impossibilita tal apresentação, pois a intangibilidade é a principal característica dos serviços (LAS CASAS, 2006).

Urdan e Urdan (2006) e Kotler e Keller (2006) relatam ser importante que os prestadores de serviços se atentem a aspectos inerentes aos serviços que impactam em seus resultados de comercialização. Os autores afirmam ainda, que a intangibilidade, 
inseparabilidade, variabilidade e perecibilidade são características que demandam atenção especial dos prestadores de serviços, uma vez que seu controle impacta diretamente nos resultados de eficiência e eficácia da organização.

\subsubsection{Composto de Marketing para Serviços}

O gerenciamento do marketing de serviços é enaltecido por um conjunto de elementos táticos que objetivam proporcionar bateria para que as empresas persigam seus alvos (KOTLER, 2000). Em detrimento de um mercado em expansão, com forte concorrência, os prestadores de serviços necessitam adotar o composto de marketing como ferramenta indispensável no gerenciamento do setor ao qual estão inseridos.

O marketing de serviços necessita de considerações especiais para sua comercialização. Não basta que um prestador de serviços tenha de decidir a respeito das características dos serviços que irá comercializar, tais como qualidade, marcas, embalagens etc. Um administrador do setor deverá, também, considerar e decidir como essa atividade será desempenhada, onde e por quem será oferecida ao mercado (LAS CASAS, 2007, p. 79).

O marketing de serviços é composto por recursos, instrumentos e técnicas controláveis, divididos em oito pilares principais, conhecidos como oito Ps, referindo-se a produto, praça, preço, promoção, processo, perfil, pessoas e produtividade e qualidade. Dittberner (2018) e Oliveira et al. (2016) afirmam que o conhecimento do composto de marketing, é necessário para uma empresa obter bons resultados mercadológicos.

Caracteriza-se como produto, àquilo que é ofertado no mercado. Em serviços, o produto refere-se ao resultado entregue ao adquirente, ou seja, o serviço em si é o produto, não podendo ser estocado. "Se um produto for mal projetado, não criará valor significativo aos clientes, mesmo que o restante dos 7 Ps sejam bem executados." (LOVELOCK; WIRTZ; HEMZO, 2011, p. 29). Conseguir suprir a necessidade e o desejo do cliente, transforma o serviço em um produto de qualidade e alimenta a perspectiva de retorno deste cliente.

A praça refere-se a todo processo de distribuição de um produto ou serviço ao públicoalvo (KOTLER; HAYES; BLOOM, 2002). Os serviços nem sempre estão atrelados a um determinado lugar, mas sim, a um momento. Como não podem ser estocados, os serviços precisam estar ao alcance dos clientes assim que haja a percepção da necessidade pelos mesmos. $O$ gestor que trabalha o marketing da prestadora de serviços, precisa estar atento quanto ao local e o momento adequado para que seus serviços sejam ofertados. 0 conhecimento pelas características da demanda, potencializa a decisão do gestor quanto ao melhor ambiente, local e data a ofertar suas atividades serviçais (KAHTALIAN, 2002).

Conforme Shimoyama e Zela (2002, p. 14), "é preciso considerar que, quando bem posicionado, o preço de um produto ou serviço é fator primordial ao sucesso de um Plano de 
Marketing". Para Las Casas (2006), comparar serviços a outros serviços é mais difícil, pois possuem aspectos e características únicas, evidenciando a particularidade de cada um. Ainda segundo o autor, na tomada de decisão pelo preço, estas particularidades devem ser adicionadas no valor, bem como os materiais utilizados, o tempo, os esforços físicos e mentais, além de tudo aquilo que custou ao processo. Segundo Kahtalian (2002, p. 26), "o serviço poderá ser caro ou barato de acordo com as expectativas de cada cliente". Caso as expectativas do cliente em relação ao serviço contratado forem desapontadas, o serviço será avaliado como de custo alto e qualidade ruim.

O prestador de serviços necessita estudar os canais de comunicação pelos quais promoverá suas atividades. Segundo os autores Lovelock e Wirtz (2006, p. 105), os "esforços de comunicação servem não apenas para atrair novos usuários, mas também para manter contato e desenvolver relacionamento com clientes existentes de uma organização". Os clientes precisam ser bem informados quanto a utilização dos serviços adquiridos, bem como, os benefícios ocasionados pelo usufruir dos mesmos. Deve-se haver diálogo informativo entre as partes, objetivando um melhor relacionamento e aproveitamento de tais serviços.

O perfil do prestador é a evidência física que o cliente busca estudar antes de adquirir qualquer serviço, pelo fato da intangibilidade não permitir a análise antecipada dos resultados finais. "O perfil refere-se ao estabelecimento em que acontecerá a prestação de serviços." (LAS CASAS, 2007, p. 79). Para maximizar a credibilidade no mercado ofertante, é necessário tangibilizar aspectos que agregue presunção de qualidade na prestação dos serviços. Tudo aquilo que é perceptível no prestador, torna-se características evidenciais para o processo decisório do cliente, portanto, quanto maior for a preocupação com a visibilidade do conjunto de valores físicos, melhor será a perspectiva deste cliente.

Para Veras e Costa (2011, p. 9) "os processos tornam-se relevantes para a diferenciação do serviço na medida em que refletem o desempenho do mesmo, procurando atingir a satisfação do cliente". Todos os procedimentos envolvidos na realização de determinado serviço, é denominado processo, podendo ou não estarem visíveis ao cliente. 0 gestor necessita otimizar tais processos, objetivando atender o cliente com maior eficiência e qualidade, entregando-o, serviços com características eficazes, que superem as perspectivas predefinidas.

Há um conjunto de pessoas que estão relacionadas a todo processo do serviço, desde a percepção de sua necessidade, até o usufruir do mesmo pelo adquirente após o prestador entregá-lo. Segundo Las Casas (2007, p. 81) "o pessoal de uma organização é muito importante para a qualidade da prestação de serviços". A qualidade do resultado final é definida pela sintonia e qualificação técnica das pessoas envolvidas no processo de realização dos serviços solicitados.

Quando um produto é adquirido, a expectativa do cliente se atenta à qualidade do mesmo. Quando um determinado serviço é solicitado, a perspectiva é que o processo do 
mesmo seja realizado de forma eficiente, garantindo agilidade, porém tal eficiência não pode afetar a qualidade do mesmo, visto que a eficácia é aguardada pelo adquirente.

Um sistema de melhora de qualidade é útil a qualquer um que lance um produto ou esteja comprometido com um serviço, ou com pesquisas, e deseje melhorar a qualidade de seu trabalho e, ao mesmo tempo, aumentar sua produção, tudo com menos mão de obra e a custos reduzidos. Os serviços precisam melhorar junto com a produção (DEMING, 1990, p. 136).

O prestador de serviços, com foco na obtenção de espaço no mercado, precisa trabalhar de maneira a produzir com eficiência, ofertando qualidade, pois em um mercado consumidor exigente e competitivo, destaca-se quem proporciona satisfação aos consumidores finais (FRITSCH, 2000).

O conhecimento dos aspectos característicos dos serviços e das ferramentas estratégicas disponibilizadas pelo composto de marketing do setor, segundo Veras e Costa (2011), proporcionam variáveis para que uma empresa persiga seus objetivos predefinidos e consiga tornar a qualidade perceptível ao seu público-alvo, transparecendo confiabilidade e respeito, características necessárias na obtenção de sucesso mercadológico.

\section{Procedimentos Metodológicos}

Para atingir os objetivos propostos neste estudo, foram entrevistados entre os dias 12 a 14 de julho de 2019, 40 (quarenta) cafeicultores do município de Caparaó, utilizando-se como instrumento, entrevistas semiestruturadas. Segundo Boni e Quaresma (2005), este tipo de procedimento favorece as respostas espontâneas, fator que oferece maior qualidade aos resultados investigados.

O estudo baseia-se em pesquisas bibliográficas para explanar conceitualmente o tema e formular as questões utilizadas nas entrevistas. Segundo Pizanni et al. (2012, p. 64), "a pesquisa bibliográfica é uma etapa fundamental antes da elaboração ou desenvolvimento de um estudo, artigo, tese ou dissertação".

A pesquisa possui caráter descritivo, "pode-se dizer que ela está interessada em descobrir e observar fenômenos, procurando descrevê-los, classificá-los e interpretá-los" (VIEIRA, 2002, p. 65). A abordagem possui característica qualitativa.

A pesquisa qualitativa é particularmente útil como uma ferramenta para determinar o que é importante para os clientes e porque é importante. Esse tipo de pesquisa fornece um processo a partir do qual questões-chave são identificadas e perguntas são formuladas, descobrindo o que importa para os clientes e porquê (MORESI, 2003, p. 69).

O estudo é caracterizado como estudo de caso. Segundo o autor Moresi (2003, p. 104), "a grande vantagem do estudo de caso é permitir ao pesquisador concentrar-se em um 
aspecto ou situação específica e identificar, ou tentar identificar, os diversos processos que interagem no contexto estudado".

Como técnica de análise dos resultados, utilizou-se a análise de conteúdo. Moraes (1999, p. 11) relata que este tipo de análise "ajuda a reinterpretar as mensagens e a atingir uma compreensão de seus significados num nível que vai além de uma leitura comum".

\section{Apresentação e Análise dos Resultados}

Produzido em nove estados brasileiros, o café é hoje um dos principais produtos da commodity agrícola brasileira, responsável por expressivos resultados macroeconômicos.

[...] o café sempre foi um produto extremamente relevante desde a época do Império até os dias de hoje. Ele tem sido o ponto forte na movimentação da economia do país, e em determinadas cidades onde a produção de café é grande a economia se torna ainda mais dependente deste produto (POLIDO et al., 2018, p. 1).

O café chegou ao Brasil no século XVIII, em 1722, pelas mãos do militar paraense Francisco de Melo Palheta. As primeiras sementes trazidas da Guiana Francesa por Palheta foram plantadas em Belém do Pará, ganhando no decorrer do século, espaço nas regiões paulistas e fluminenses, chegando ao estado de Minas Gerais nas décadas que antecediam o final do século (MOTTA SOBRINHO, 1978).

As primeiras décadas do século XIX marcaram a expansão do cultivo e produção do café, influenciado principalmente pelo declínio da economia do ouro em determinadas regiões de extração e o crescimento da entrada de escravos no país, aspectos que aumentavam o contingente de mão de obra nos cafezais (MOTTA SOBRINHO, 1978; LIMA, 1981). Nas quatro últimas décadas do século XIX, o apogeu cafeeiro reduziu e se manteve estagnado até as duas primeiras décadas do século XX.

O café, no último quartel do século XIX, iria atravessar sua maior crise, resultantes dos males de sua estrutura econômica agravados pela abolição, pelo receio de insolvência dos cafeicultores, pela concorrência de novas zonas produtora, onde a cafeicultura fora estabelecida de modo mais racional, com o esforço do trabalho livre do imigrante europeu, italiano, principalmente, e, por último, pela superprodução (MOTTA SOBRINHO,1978).

Momentos adversos marcaram o cultivo de café no Brasil no século XX, com períodos de acentuada produção, valorização e crises que afetaram diretamente o mercado produtor do grão (CARONE, 1978; 1982; 1988). Com o objetivo de conquistar novos mercados consumidores e maximizar os preços do café, iniciou-se a partir de 1960, segundo Guimarães (2016), a produção de cafés especiais, com melhor agregação de qualidade aos grãos produzidos, conquistando notoriedade no decorrer dos anos seguintes e alcançando os objetivos inicias de crescimento do mercado consumidor e preços satisfatórios.

Iniciado há quase 300 anos atrás, a produção de café no Brasil é predominantemente exercida por mini e pequenos cafeicultores espalhados por cerca de 1.900 municípios 
(SORIO, 2015). Segundo a Associação Brasileira da Indústria de Café - ABIC (2019), cerca de $35 \%$ do consumo mundial do grão, explanando sua relevância na economia nacional.

Segundo levantamento da Companhia Nacional de Abastecimento - CONAB (2019), o Brasil deve alcançar uma produção de 50,92 milhões de sacas de café em 2019. Para o Instituto Brasileiro de Geografia e Estatística - IBGE (2019b), a produção nacional alcançará 53,9 milhões de sacas no ano. Tanto a CONAB quanto o IBGE, usam como base para seus respectivos levantamentos estimativos, o período produtivo entre os meses de abril a novembro. Já a Organização Internacional do Café - OIC (2018), que faz sua estimativa com base no ano-safra, entre abril do presente ano e março do ano vindouro, safra 2019/2020, aponta uma produção brasileira de 58,5 milhões de sacas de café.

Minas Gerais é o maior estado produtor de café do país. Segundo o levantamento da CONAB (2019), estima-se que o estado terá uma produção de 26,44 milhões de sacas em 2019, representando 52\% da estimativa para a produção nacional. Estima-se ainda, que a mesorregião da zona da mata mineira produzirá 6,14 milhões de sacas de café em 2019, com percentual aproximado de $23 \%$ da produção estadual e $12,1 \%$ da produção nacional.

O município de Caparaó, integrante da mesorregião da zona da mata de Minas Gerais, possui conforme Censo do IBGE (2010), 5.209 habitantes, dos quais, 61,5\% residem na zona rural. Conforme o último Censo Agropecuário do IBGE (2017), Caparaó possui 546 estabelecimentos agropecuários voltados para a produção cafeeira, ou seja, propriedades que possuem acima de 50 pés de café. Segundo a Empresa de Assistência Técnica e Extensão Rural - EMATER (2019), tais propriedades estão distribuídas em 6.300 hectares. Ainda segundo a empresa, o município produziu 138.600 sacas de café arábica em 2018.

De acordo com levantamento feito através de entrevistas com 40 cafeicultores do município de Caparaó, verifica-se que $85 \%$ dos entrevistados têm na produção do café a principal fonte de renda financeira, cujo café arábica é a única variedade cultivada em suas propriedades, comumente classificados quanto à qualidade, como arábica bebida dura, arábica bebida riada e arábica bebida rio'.

A produção de cafés especiais ainda é muito pequena em Caparaó e dificilmente encontra-se mercado no próprio município, sendo necessário a comercialização dos grãos em outras cidades. Questionados sobre a possibilidade de se produzir cafés com peculiaridades de suavidade e doçura intensa, famosos gourmets, caso os corretores de cafés do município abrangessem a aquisição dos mesmos, $12 \%$ dos entrevistados disseram que considerariam iniciar a produção, ainda que em baixa escala inicial, apontando a já dita dificuldade interna

\footnotetext{
1 Trata-se de um sistema de classificação dos sabores característicos de cafés da espécie arábica, definidos como de bebidas finas de alta qualidade, conhecidos no mercado como cafés especiais ou gourmet, enquadradas como do grupo I (Cafeicultura, 2019).
} 
de venda e a mão de obra trabalhosa, como fatores que dificultam a produção de grãos com qualidades superiores.

A comercialização dos grãos produzidos em Caparaó se dá geralmente por corretores, conhecidos também como atravessadores do setor cafeeiro, responsáveis por comprar os grãos dos produtores e fazer com que os mesmos cheguem até os grandes comércios do setor, responsáveis pelas comercializações com todo país e exportações do produto.

Identificou-se ainda, que os entrevistados reclamam da variação na classificação de suas produções de café, uma vez que esta avaliação é realizada por critérios subjetivos, implicando diretamente na variabilidade da prestação do serviço dos corretores, que agem de acordo com critérios que não são amplamente divulgados aos cafeicultores.

Apenas $30 \%$ dos entrevistados disseram fazer uma única venda dentro da safra, ou seja, comercializam toda a produção anual de uma única vez, enquanto majoritariamente, outros $70 \%$ disseram beneficiar e vender os grãos colhidos em momentos distintos dentro de uma mesma safra, de acordo com a necessidade financeira momentânea e/ou valor de mercado do grão. Destes 28 produtores que relataram beneficiar e comercializar em lotes distintos seus grãos produzidos, $57 \%$ disseram ser corriqueiro a venda de suas produções para mais de um corretor dentro da mesma safra.

Quando perguntados sobre a venda direta de suas produções, 32\% dos cafeicultores entrevistados disseram já terem vendido parte dos lotes dos grãos produzidos a corretores de outros municípios, por terem encontrado melhores oportunidades na negociação.

O preço pago ao produtor, atrelado à credibilidade do corretor, são os principais quesitos observados na hora de escolher para quem vender o café. 92\% dos entrevistados afirmaram que somente levam amostras dos grãos para corretores que transmite confiança, diante de seus históricos de atuação no mercado. Após analisadas as amostras, o corretor oferece o lance inicial pelos grãos, onde, $80 \%$ dos produtores afirmaram fechar a venda com aquele que oferece o melhor valor ao produto, enquanto $20 \%$ dos entrevistados, tem o prazo de pagamento como fator preponderante para fechar a venda.

Quando perguntados sobre o processo de transporte do café vendido, unanimemente, os entrevistados disseram que a retirada das sacas do produto de suas propriedades, devem ser realizadas o mais rápido possível e este serviço sempre é realizado pelo corretor. Quanto a isso, $90 \%$ disseram que o tempo entre a negociação e a retirada dos grãos de suas propriedades é satisfatório, enquanto $10 \%$ acham necessário que o tempo de espera pela retirada do café de suas propriedades deva ser agilizado, pois há incidência de roubos em propriedades rurais na região, principalmente roubos a cargas de cafés armazenados, fato que os preocupam.

Quando beneficiado, os grãos são colocados em sacas com peso médio de 60 quilogramas, de acordo com o padrão mercadológico, porém, é comum a oscilação entre balanças. Quando o café chega ao local de armazenagem mantido pelo comprador, o mesmo 
é pesado novamente, afim de conferir a exatidão final do peso, podendo haver corte quando o peso é menor do que o padronizado ou crescimento, quando o peso supera o padrão estabelecido mercadologicamente. Perguntados sobre a presença no acompanhamento do peso final, $27 \%$ dos cafeicultores entrevistados disseram fazer o acompanhamento da pesagem, enquanto $73 \%$ disseram confiar nos resultados repassados pelos compradores, uma vez que, segundo eles, a oscilação é mínima.

Segundo os entrevistados, o recebimento de brindes como calendários, bonés, chaveiros, entre outros acessórios, é comum quando se efetua a venda de café a um corretor. Perguntados sobre ações de marketing dos corretores, $77 \%$ dos participantes da entrevista disseram já terem ouvido comerciais de comércios de corretagem do município em rádios e/ou visualizado divulgações em eventos, porém, unanimemente, disseram que tais ações não trazem nenhum incentivo comercial, uma vez que não apresentam seus diferenciais competitivos e os dados realmente apresentados, como endereço e telefone, já são de amplo conhecimento, devido a área do município ser pequena, fator que maximiza o conhecimento entre pessoas.

A safra de café compreende-se normalmente entre os meses de maio e setembro, com oscilações mediante questões regionais. Quando perguntados sobre a comercialização dos grãos produzidos em meses de entre safra, caso seja guardado lotes objetivando melhores preços, por exemplo, $87 \%$ dos cafeicultores disseram que mesmo com a oferta reduzida de grãos ao mercado, há facilidade de buscar negociações com corretores, pois os comércios de corretagem são mantidos ativos nos meses de ofertas ociosas.

Quanto a fidelização, a pesquisa aponta que apenas 2 produtores dos 40 entrevistados disseram ter o hábito de vender seus cafés a um único corretor todos os anos. Um deles justificou essa opção de fidelização devido ao parentesco com determinado corretor, enquanto o outro apontou a amizade e confiança para com certo corretor, como fatores que estabelecem a fidelização comercial entre eles.

Não é incomum no mercado de comercialização de cafés, perceber alguns corretores que ocasionam prejuízos a clientes. Geralmente utilizam-se como pretexto a instabilidade econômica, as crises financeiras, entre outros. Diante de tais fatos, a credibilidade dos serviços de corretagem é verificada através do histórico de atuação de determinado corretor dentro do mercado. O estudo aponta a preocupação dos cafeicultores em analisar a conduta mercadológica dos corretores antes de fecharem acordos comerciais, fato que demonstra a necessidade dos corretores de trabalharem em conformidade com os acordos, principalmente, no cumprimento de datas acordadas no momento da negociação.

O estudo realizado aponta que o fator preço é um elemento fundamental na negociação entre produtor e corretor. Sabe-se que o preço é altamente variável, com oscilações diárias de acordo com o mercado de commodities. De acordo com os relatos, 
verifica-se que o preço de um determinado lote de café depende primeiramente, das avaliações manuais, dos aspectos físicos, a homogeneidade de cor e tamanho, seguido do paladar, oriundo da degustação dos grãos. Essa avaliação é feita de forma manual e sensitiva, proporcionando uma variação dos preços atribuídos a cada lote, por cada corretor. Tal variação na precificação ajuda a explicar a venda de lotes de cafés para diversos corretores, mesmo se tratando de uma mesma safra. Os cafeicultores buscam sempre melhores condições em suas negociações.

Por fim, identificou-se que $12 \%$ dos entrevistados estariam interessados em atuar com a produção de cafés especiais ou gourmets. Sabe-se que há uma crescente produção desses cafés no Brasil, contudo, no mercado local essa categoria de produtos ainda não está sendo negociada como avaliam os cafeicultores.

\section{Conclusão}

O presente trabalho almejou conhecer as relações comerciais entre os corretores de café do município de Caparaó e os produtores do grão, buscando entender o que pensa tais produtores sobre o mercado comprador de suas produções. Foi utilizado o marketing de serviços como parâmetro de entendimento, já que tais ferramentas do marketing de serviços são estratégias que possibilitam tangibilizar os serviços prestados pelos corretores de café, apresentando ao cliente, evidências de qualidade mercadológica.

Em um mercado saturado, com vários escritórios de corretagem não apenas no município, mas também em municípios vizinhos, trabalhar com a comercialização de café é algo que necessita de uma comunicação mercadológica direta e objetiva com o cafeicultor, afim de alcançar vantagens competitivas.

As entrevistas aplicadas evidenciaram a padronização de alguns procedimentos, a falta de inovação nas relações mercadológicas e pouca competitividade nos diferenciais de marketing de serviços aplicados pelos corretores no município de Caparaó. Ainda foi identificado, que os processos relacionados às etapas da negociação e comunicação com os cafeicultores, não estão pautadas na literatura de marketing de serviços.

Evidenciou-se que a variável preço de compra e venda, é a principal ferramenta de negociação entre cafeicultores e corretores. Percebe-se que não há muito esforço por parte dos corretores de trabalharem as características do marketing de serviços. Tendo em vista a expansão produtiva cafeeira na Região do Caparaó, enseja-se a possibilidade de novas linhas de estudo sobre o tema, buscando identificar também, o que pensam os corretores sobre as estratégias mercadológicas utilizadas para a prestação de serviços. 


\section{REFERÊNCIAS}

ABIC - ASSOCIAÇÃO BRASILEIRA DA INDÚSTRIA DE CAFÉ. Consumo mundial de café atinge 165 milhões de sacas no ano cafeeiro 2018-2019. ABIC, 2019. Disponivel em: <http://abic.com.br/consumomundial-de-cafe-atinge-165-milhoes-de-sacas-no-ano-cafeeiro-2018-2019/>. Acesso em: 16 abril 2019.

BONI, V.; QUARESMA , S. J. Aprendendo a entrevistar: como fazer entrevistas em Ciências. Revista Eletrônica dos Pós-Graduandos em Sociologia Política da UFSC, Santa Catarina, v. 2, n. 1, p. 6880, Julho 2005. ISSN 1806-5023.

BOONE, L. E.; KURTZ, D. L. Marketing Contemporâneo. 8ª ed. Rio de Janeiro: LTC, 1998.

CARONE, E. A Segunda República: 1930-1937. 3ª . ed. São Paulo: Difel, 1978.

CARONE, E. A Terceira República: 1937-1945. 2ª . ed. São Paulo: Difel, 1982.

CARONE, E. A República Velha: Instituições e Classes Sociais. 5ª ed. São Paulo: Bertrand Brasil, v. $1,1988$.

COBRA, M. Administração de Marketing no Brasil. 3ạ. ed. Rio de Janeiro: Elsevier, 2009.

CONAB - COMPANHIA NACIONAL DE ABASTECIMENTO. Café. Acompamento da Safra Brasileira, Brasília, v. 5, n. 2, p. 1-61, Maio 2019. ISSN 2318-7913.

DEMING, W. E. Qualidade: A Revolução da Administração. 1a. ed. Rio de Janeiro: Saraiva, 1990.

DITTBERNER, C. Desenvolvimento do composto de marketing de serviços em uma lancheria. 2018. 53 p. Dissertação (Administração) — Universidade de Santa Cruz do Sul.

EMATER - EMPRESA DE ASSISTÊNCIA TÉCNICA E EXTENSÃO RURAL. Perfil Produtivo Municipal Caparaó. $\quad 2019 . \quad$ EMATER, em: <http://portaldocafedeminas.emater.mg.gov.br/Perfil/Municipio/141>. Acesso em: 30 Maio 2019.

FARIA, G. G. de S. Atributos valorizados pelos consumidores de farmácias de manipulação residentes no Bairro Glória. 2011. 57 p. Dissertação (Administração) - Universidade Federal do Rio Grande do Sul.

FRITSCH, D. Z. A importância da qualidade na prestação de serviços. Revista de Educação do Cogeime, São Paulo, v. 9, n. 17, p. 65-70, Dezembro 2000. ISSN 2358-9299.

GUIMARÃES, E. R. Terceira onda do café: Base Conceitual e Aplicações. 2016.135 p. Dissertação (Administração) - Universidade Federal de Lavras.

HANSEN, G. A contribuição da comunicação de marketing na relação entre os alunos e a instituição de ensino: $O$ caso dos cursos técnicos do Instituto de Educação Ivoti. 2016. 149 p. Dissertação (Administração) — Universidade de Santa Cruz do Sul.

IBGE - INSTITUTO BRASILEIRO DE GEOGRAFIA E ESTATíSTICA. Brasil em Síntese. 2010. Disponivel em: <https://cidades.ibge.gov.br/brasil/mg/caparao/panorama>. Acesso em: 30 Maio 2019. IBGE - INSTITUTO BRASILEIRO DE GEOGRAFIA E ESTATÍSTICA. Indicadores IBGE: Contas Nacionais Trimestrais. 2019a. Disponivel em: <ftp://ftp.ibge.gov.br/Contas_Nacionais/Contas_Nacionais_Trimestrais/Fasciculo_Indicadores_IBGE/p ib-vol-val_201804caderno.pdf>. Acesso em: 18 Março 2019. 
IBGE - INSTITUTO BRASILEIRO DE GEOGRAFIA E ESTATÍSTICA. Indicadores IBGE: Levantamento Sistemático da Produção Agrícola. 2019b. Disponivel em: $<$ https://www.ibge.gov.br/estatisticas/economicas/agricultura-e-pecuaria/9201-levantamentosistematico-da-producao-agricola.html?=\&t=downloads>. Acesso em: 30 Maio 2019. IBGE - INSTITUTO BRASILEIRO DE GEOGRAFIA E ESTATÍSTICAS. Censo Agropecuário. 2017. Disponivel em: <https://cidades.ibge.gov.br/brasil/mg/caparao/pesquisa/24/76693>. Acesso em: 2019 Maio 30.

KAHTALIAN, M. Administração de Marketing. Gestão Empresarial, Curitiba, v. 3, n. 1, p. 19-29, 2002. KOTLER, P. Administração de Marketing: Análise, Planejamento, Implementação e Controle. 5ª ed. São Paulo: Atlas, 1998.

KOTLER, P. Administração de Marketing: A edição do novo milênio. 10ª ed. São Paulo: Pearson Prentice Hall, 2000.

KOTLER, P.; HAYES, T.; BLOOM, P. N. Marketing de Serviços Profissionais: Estratégias inovadoras para impulsionar sua atividade, sua imagem e seus lucros. 2ª . ed. São Paulo: Manole, 2002.

KOTLER, P.; KELLER, K. L. Administração de Marketing. 12ª . ed. São Paulo: Pearson Prentice Hall, 2006.

LAS CASAS, A. L. Marketing de Serviços. 2ª ed. São Paulo: Atlas, 2000.

LAS CASAS, A. L. Administração de Marketing: Conceitos, planejamento e aplicações à realidade brasileira. 1‥ ed. São Paulo: Atlas, 2006.

LAS CASAS, A. L. Marketing de Serviços. 5ª ed. São Paulo: Atlas, 2007.

LIMA, J. H. Café e Indústria em Minas Gerais: 1870-1920. 1a. ed. Petrópolis: Vozes, 1981.

LOVELOCK, C.; WIRTZ, J. Marketing de Serviços: Pessoas, tecnologia e resultados. 5‥ ed. São Paulo: Pearson Prentice Hall, 2006.

LOVELOCK, C.; WIRTZ, J.; HEMZO, M.. Marketing de Serviços: Pessoas, tecnologia e estratégia. 7ạ . ed. São Paulo: Pearson Prentice Hall, 2011.

LOVELOCK, C.; WRIGHT, L. Serviços: Marketing e Gestão. 1a. ed. São Paulo: Saraiva, 2001.

MORAES, R. Análise de Conteúdo. Revista Educação, Porto Alegre, v. 22, n. 37, p. 7-32, Março 1999. ISSN 1981-2582.

MORESI, E. Metodologia da Pesquisa. 2003. 108 p. Dissertação (Gestão do Conhecimento e Tecnologia da Informação) - Universidade Católica de Brasília.

MOTTA SOBRINHO, A. A Civilização do Café. 3a. ed. São Paulo: Brasiliense, 1978.

OIC - ORGANIZAÇÃO INTERNACIONAL DO CAFÉ. Relatório sobre o mercado de Café. OIC, 2018.

Disponivel

em:

<http://consorciopesquisacafe.com.br/arquivos/consorcio/publicacoes_tecnicas/relatorio_oic_dezembr o_2018.pdf>. Acesso em: 21 Abril 2019.

OLIVEIRA, J. L. D. et al. Composto de marketing no setor de comércio e serviços. Revista da Faculdade de Administração e Economia, São Bernardo do Campo, v. 7, n. 1, p. 31-47, Dezembro 2015. ISSN 2176-9583.

PIRES, R. G et al. A utilização de ferramentas mercadológicas: um estudo de caso com empreendedores individuais das Comarcas de Carangola-MG e Tombos-MG. In: Gestão e tecnologia como influenciadores de uma nova economia. São Paulo - SP: PoloBooks, 2019. 
PIZZANI, L. et al. A arte da pesquisa bibliográfica na busca do Conhecimento. Revista Digital de Biblioteconomia e Ciência da Informação, Campinas, v. 10, n. 1, p. 53-66, Dezembro 2012. ISSN 1678-765X.

POLIDO, N. B. et al. O empreendedorismo no mercado de cafés especiais: Um estudo de caso com cafeicultores da região do Caparaó-MG. In: Congresso de Administração, Sociedade e Inovação, Rio de Janeiro, RJ. Anais (on line) 2018. Disponível em:

<https://www.even3.com.br/anais/11casi/119131-o-empreendedorismo-no-mercado-decafes-especiais--um-estudo-de-caso-com-cafeicultores-da-regiao-do-caparao-mg/>. Acesso em: 01 agosto 2019.

RATHMELL, J. M. O que se entende por serviços? Revista de Marketing, Chicago, v. 30, n. 4, p. 3236, Outubro 1966.

ROCHA, A. D.; CHRISTENSEN,. Marketing: Teoria e prática no Brasil. 2ª ed. São Paulo: Atlas, 1999. SILVA, L. V. et al. Marketing de lugares e suas perspectivas na revolução do café de qualidade: um estudo na região de Caparaó - MG. In: IV Seminário Científico da UNIFACIG - e II Jornada de Iniciação Científica da UNIFACIG, Manhuaçu, MG. Anais (on line) 2018. Disponível:

<http://pensaracademico.facig.edu.br/index.php/semiariocientifico/article/view/812/713> Acesso em: 01 agosto 2019

SHIMOYAMA, C.; ZELA,. Administração de Marketing. Gestão Empresarial, Curitiba, v. 3, n. 1, p. 118, 2002.

SORIO, A; Coordenador. Reposicionamento estratégico das indústrias processadoras de café do Brasil: propostas para sistematização de políticas públicas e estratégias de negócios, Passo Fundo: Méritos, p. 222, 2015.

STEFANO, S. R. et al. Satisfação do cliente nos serviços prestados pela Sercomtel Celulares. VII SEMEAD. São Paulo: USP, 2004. Disponível em: $<$ http://sistema.semead.com.br/7semead/paginas/artigos\%20recebidos/marketing/MKT70__Satisfa\%E7\%E3o_do_Cliente_nos_servi\%E7os_Ser.PDF>. Acesso em: 16 Abril 2019. URDAN, F. T.; URDAN,. Gestão do Composto de Marketing. 1ª . ed. São Paulo: Atlas, 2066. VARADARAJAN, R. Estratégia estratégica de marketing e marketing: Domínio, definição, questões fundamentais e premissas fundamentais. Jornal da Academia de Ciências de Marketing, v. 38, n. 2, p. 119-140, Abril 2010. ISSN 0092-0703.

VERAS, J. G. F. de; COSTA, J. de O. Análise dos 8 P's do marketing de serviços na empresa Plano de Assistência Familiar. 2011. 33 p. Dissertação (Administração) — Universidade Estadual da Paraíba.

VIEIRA, V. A. As tipologias, variações e características da pesquisa de marketing. Revista da Faculdade de Administração e Economia, São Bernardo do Campo, v. 5, n. 1, p. 61-70, Abril 2002. ISSN 2176-9583. 